\title{
ANASTOMOTIC ENLARGEMENT AND ISCHÆMIC MYOCARDIAL DAMAGE
}

\author{
BY \\ W. F. M. FULTON* \\ From the Department of Materia Medica and Therapeutics, University of Glasgow
}

Received March 21, 1963

It has been observed for a long time that the territorial extent of muscle damage consequent on coronary artery occlusion usually falls considerably short of the entire muscle mass that had been anatomically dependent on the artery in question. This has been noted by a number of workers in the experimental field since the time of Hirsch and Spalteholz (1907). Herrick (1912) cited the observations of several contemporaries who considered that the discrepancy between the extent of myocardial lesions and arterial territories was evidence for the existence of collateral circulation in the heart of man. Even at that time there was anatomical confirmation that this was so, and further confirmation has been obtained in the present investigation (Fulton, 1963a). Notable contributions have been made to this topic by later workers, including Schlesinger (1938) and Zoll, Wessler, and Blumgart (1951).

In the present investigation a considerable correlation was found between the anatomical distribution of the coronary arteries, the site, number, and completeness of the anastomotic development found at death, and the distribution of myocardial damage. At the same time the findings emphasized the complexity of the relation between coronary artery occlusion and cardiac muscle damage, so that no single factor could satisfactorily explain all the variants that occurred. Before considering the role of collateral blood supply in this connexion, it may be worth while to list some factors that may influence the balance between myocardial demands and coronary blood supply.

\section{Myocardial Demands and Coronary Blood Supply}

(1) Coronary Flow Volume. Anatomical importance of the occluded artery, site of occlusion in that artery, and completeness of occlusion. Immediately available collateral channels, their site, course, and dimensions. Patency of other coronary arteries, and of proximal branches of the occluded artery. Systemic blood pressure at the time of occlusion, and thereafter. Coronary artery 'spasm' (?). Encroachment on diastole by tachycardia, and the effects of arrhythmias. Valvular disease, particularly aortic. Narrowing of coronary ostia.

(2) Quality of the Blood. Anæmia; hypoxia from respiratory insufficiency, high altitude, carbon monoxide poisoning, and hypoglycæmia.

(3) Myocardial Demand. Increased work as in effort, hypertension, aortic valvular disease. Ventricular hypertrophy. Tachycardia, as in excitement, exertion, arrhythmias, fevers. Hyperthyroidism.

Against so potentially complex a background it may seem that few conclusions about any one factor could be derived from observations based on a relatively small series. And yet this does not seem to be so; for the available collateral blood supply did seem to be outstandingly the most important single factor determining the extent of muscle damage that followed occlusion of a coronary artery.

\footnotetext{
* Formerly Research Assistant in Cardiology in the University of Edinburgh. Present address: Johns Hopkins Hospital, Baltimore, Maryland, U.S.A.
} 


\section{MATERIAL AND Methods}

A series of 59 hearts was investigated post mortem by a method that included stereo-arteriography. The series comprised 25 cases of coronary artery disease, 17 cases with heart disease other than coronary artery disease, 12 normal hearts, and 5 hearts that were normal save for increase in heart weight beyond normal limits. The material and technique of examination have been described in greater detail elsewhere (Fulton 1960, 1963a, c).

A radio-opaque injection medium (bismuth-oxychloride-gelatin) was introduced into both coronary arteries under controlled pressure. Differential pressure gradients were employed during the course of injection. The maximum pressure used routinely was $150 \mathrm{~mm}$. $\mathrm{Hg}$. Stereoradiography was employed throughout, for the intact heart and for all portions of the heart yielded by partial dissection. The method of preliminary dissection divided the heart into (1) the atrial "cap", (2) the "basal block", which was unfolded by suitable incisions, (3) one or more transventricular sections, and (4) the apex. The procedure was specially devised for the display of changes in the entire coronary artery tree together with the distribution of myocardial damage in relation to the circulatory anatomy. The universal employment of stereoscopy and the use of transventricular sections contributed to the recognition of changes in the deeper layers of the ventricles, both myocardial and arteriographic. The occlusive lesions of the coronary arteries were examined after excision by a method of serial mounting of $2 \mathrm{~mm}$. thick sections, with selective histology. It is intended to include this method with a subsequent publication. The details have been outlined (Fulton, 1960).

When all available information was collected and correlated in each case it was possible to assemble a composite, three-dimensional picture of the detail of the occlusive lesions, the anatomical setting in which they had arisen, the extent and distribution of the myocardial damage that had resulted from them, and the pattern of anastomotic enlargement that was found at death. From a judicious consideration of the clinical events and the gross and histological features of the myocardial lesions, it was usually possible to arrive at a presumptive opinion of the duration and sequence of the changes found. Distinction between anastomotic changes already present at the time of coronary artery occlusion and the changes provoked by, and subsequent to, occlusion were of course speculative, except where occlusion had been survived for only a short period.

\section{OBSERVATIONS}

A. General Comment. Although one can, for instance, measure individual anastomoses and can estimate the approximate proportion of a given arterial territory that has undergone necrosis, the observations under consideration are complex and largely qualitative in nature. For this reason it has not been possible to present all the relevant findings in tabulated form, from which an independent observer could draw his own conclusions. Accordingly my conclusions are put forward without the accompanying support of more than a fragment of the evidence from which they have been derived. They were reached through repeated examination of the evidence in each case and in the series as a whole. Much of the original evidence is to be found in the author's M.D. thesis (Fulton, 1960). However, it may perhaps be conceded that conclusions on this topic would probably have been less valid had they been based solely on statistical manipulation of numerical quantities. Tables I and II give an indication of the general scope of the observations.

B. Regional and Zonal Infarction. It has been found helpful to distinguish between two types of myocardial damage, in regard to distribution: regional and zonal (Fulton, 1956). Type examples of regional myocardial infarction are illustrated in Fig. 6, $\mathrm{A}$ and $\mathrm{B}$; while $\mathrm{C}$ shows inner zonal necrosis. As might be expected many gradations and combinations of these two forms of myocardial damage were found in this series. The distinction between them, however, is not merely descriptive. Evidence will be presented that relates the distribution of myocardial damage to the nature and extent of the underlying changes in the coronary circulation.

Correlation of arterial and myocardial changes was often best displayed by the transventricular sections, when examined in conjunction with the stereograms of the intact heart. Accordingly selected examples of transverse sections will be used for purposes of illustration. Conclusions were of course derived from examination of the entire available evidence. 
TABLE I

\begin{tabular}{c|c|c|c|c}
\hline \multicolumn{2}{c|}{$\begin{array}{c}\text { Arteries, the seat of } \\
\text { occlusion }\end{array}$} & \multicolumn{3}{|c}{ Myocardial damage } \\
\cline { 4 - 5 } \multicolumn{1}{c}{ Duration } & No. & None & Focal only & Massive \\
\hline <4 weeks & 15 & $1^{*}$ & 1 & $13(+1 \dagger)$ \\
$\begin{array}{l}\text { 4 weeks to 6 months } \\
\text { >6 months }\end{array}$ & 55 & 0 & 0 & 5 \\
\hline & 45 & 2 & 7 & 17 \\
\hline
\end{tabular}

'Occlusions' were all complete at death or were canalized-once-complete. Severe narrowings without good evidence of former complete occlusion are not included. The left common coronary is regarded as two arteries with two territories.

* Complete occlusion of terminal portion of a left circumflex artery, beyond the origin of a branch that was larger than the parent artery.

$\dagger$ Death took place within one hour. In the setting in which occlusion occurred it seemed inevitable that massive infarction would have resulted although only focal damage was found.

$\ddagger$ Complete occlusion of a small right coronary artery that took no part in the blood supply to the left ventricle.

TABLE II

Severity of Myocardial Damage in Relation to Distribution of Main-stem Coronary ARTERY OCCLUSIVE LeSIONS (25 CASES)

\begin{tabular}{|c|c|c|c|c|c|c|}
\hline & \multirow{2}{*}{$\begin{array}{l}\text { Arterial } \\
\text { situation } \\
\text { at death }\end{array}$} & \multicolumn{5}{|c|}{$\begin{array}{l}\text { Myocardial damage in territory } \\
\text { of most recently occluded artery(s) }\end{array}$} \\
\hline & & None & $\begin{array}{c}\text { Focal } \\
\text { only }\end{array}$ & $<\frac{1}{3}$ & $\frac{1}{3}-\frac{2}{3}$ & $\begin{array}{l}\text { Nearly } \\
\text { total }\end{array}$ \\
\hline $\begin{array}{l}\text { One artery occluded, others 'unob- } \\
\text { structed' } \\
\text { One artery occluded, one other artery } \\
\text { narrowed } 2-1 \mathrm{~mm} \text {. } \\
\text { One artery occluded, one other previ- } \\
\text { ously occluded } \\
\text { One artery occluded, two others previ- } \\
\text { ously occluded } \\
\text { Left coronary common trunk occlusion } \\
\text { Old occlusion of two or three arteries, } \\
\text { time relations uncertain }\end{array}$ & 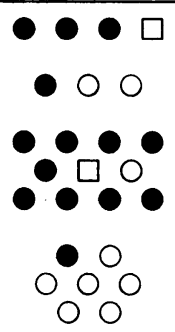 & & $\begin{array}{ll}\circ & 1 \\
\circ & 0\end{array}$ & $\begin{array}{l}\square \\
0 \\
0 \\
0 \\
0\end{array}$ & $\begin{array}{c}0 \\
0 \\
0\end{array}$ & 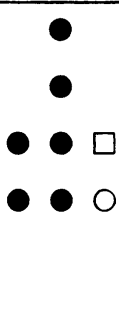 \\
\hline
\end{tabular}

$0=<1$ month in duration. $\square=1-6$ months in duration. $O=>6$ months in duration. $O=<1$ month and $>6$ months in duration.

The entries refer only to the situation found at death, there being, therefore, one entry for each case. 'Unobstructed' arteries had a lumen greater than $2 \mathrm{~mm}$. in diameter. 'Main-stems' refer to the three main coronary arteries (the right coronary artery, the anterior descending coronary artery, and the left circumflex coronary artery) and, where indicated, the left coronary common trunk.

\section{EXAMPLES}

(1) A 73-year-old woman (J.C.). In Fig. 1 may be seen one of the stereo-pairs of the arteriogram of an intact heart. The gap in the continuity in the anterior descending artery represents thrombotic occlusion of some eight days' duration (as judged from the clinical features). The small branches of this artery distal to the occlusion are incompletely filled, because there was widespread confluent necrosis of its territory (Fig. 2, A and B). Indeed, death resulted from this lesion, with rupture of the interventricular septum. Despite a superficial communication of moderate size between the right coronary artery and the anterior descending artery near the apex, it was evident that the collateral blood flow to the distal territory of the anterior descending artery was insufficient to avert massive infarction. The state of the deep vessels may be seen in crosssection through the ventricles (Fig. 2, A). It is noteworthy that communications across the interventricular septum (from branches of the right coronary artery) were poorly developed and the vessels of the subendo- 
Fig. 1.-Arteriogram of the intact heart (Case J.C.). Thrombotic occlusion of the anterior descending artery. Poor injection of the territory distal to occlusion on account of recent massive necrosis. An enlarged anastomotic communication between right coronary artery and anterior descending artery is seen near the apex. Otherwise the small vessels show only slight increase over the normal pattern. (See also Fig. 2 and 8.)

cardial plexus showed little departure from the normal pattern (cf. Fig. 3 which shows the normal appearances and Fig. 4 and 5 which are examples of adaptive enlargement in disease). In this instance, therefore, massive regional infarction of the type indicated in Fig. 6, A, followed acute coronary artery occlusion in the presence of a pattern of collateral circulation that had shown but little increase over the normal, as in Fig. 6, AA. 


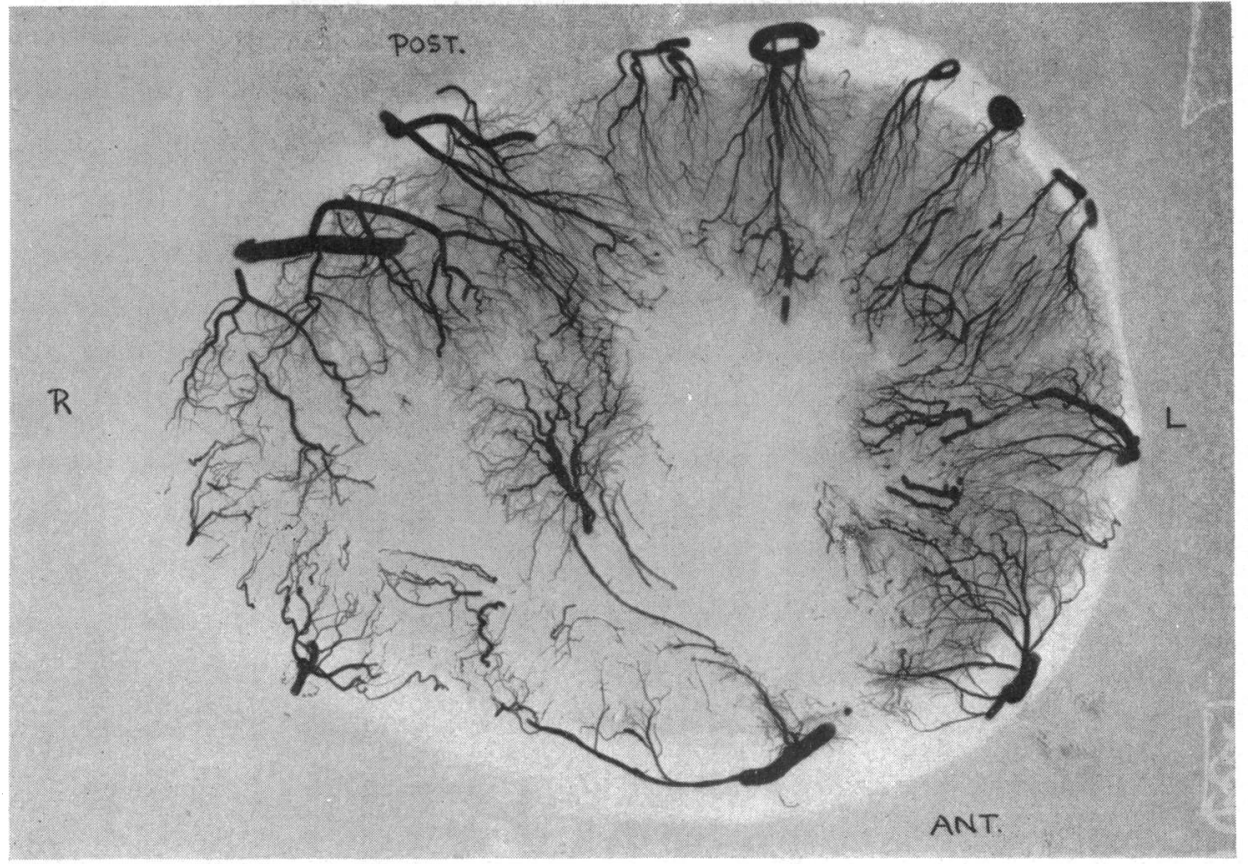

A

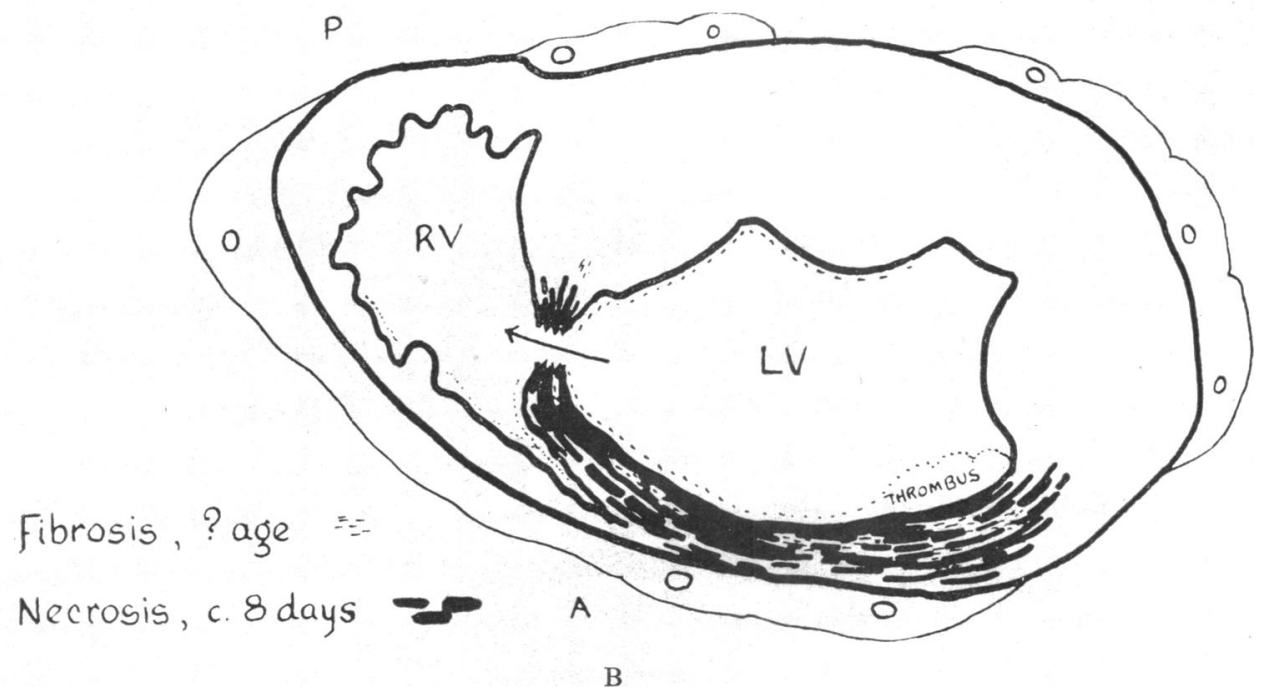

FIG. 2.-Transventricular section (Case J.C.). (A) The arteriographic pattern. (B) The distribution of myocardial damage.

Such anastomotic enlargement as was present could be related to previous, old-standing narrowing of the anterior descending artery to a diameter of $1 \mathrm{~mm}$. at the site that was finally completely occluded. A scale drawing of the coronary circulation in this case appears in Fig. 8 which may be compared with the normal appearances in Fig. 7. 


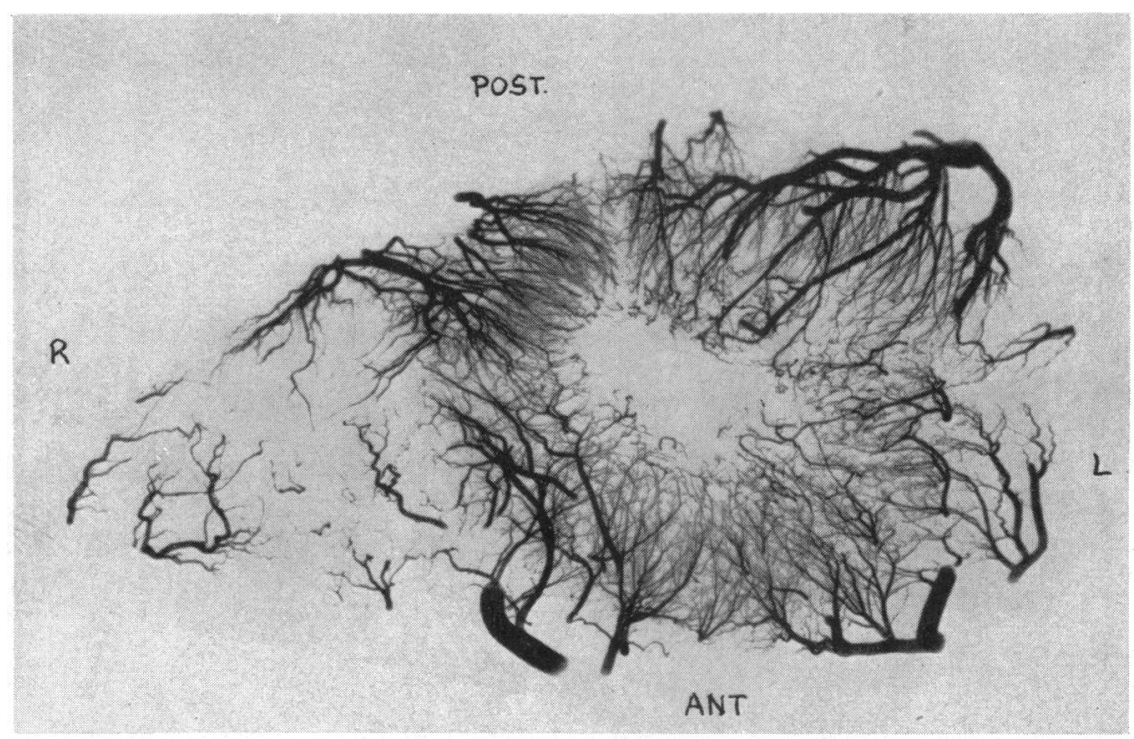

Fig. 3. -Transventricular section: normal arteriographic pattern. (See Fig. 7-same case.)

(2) A 62-year-old woman (H.E.). In this case myocardial infarction was an incidental finding at autopsy. The incident had not been recognized clinically, and at no time was there angina. Death was due to complications following operation for gastric carcinoma. Fig. 4 illustrates the pattern of enlargement of deeplyplaced anastomoses, which may be compared with the distribution and extent of myocardial damage by reference to Fig. 9, which also contains a scale drawing of the coronary artery circulation. Muscle damage was patchy in distribution and much less extensive than in the case (J.C.) first described. It was again

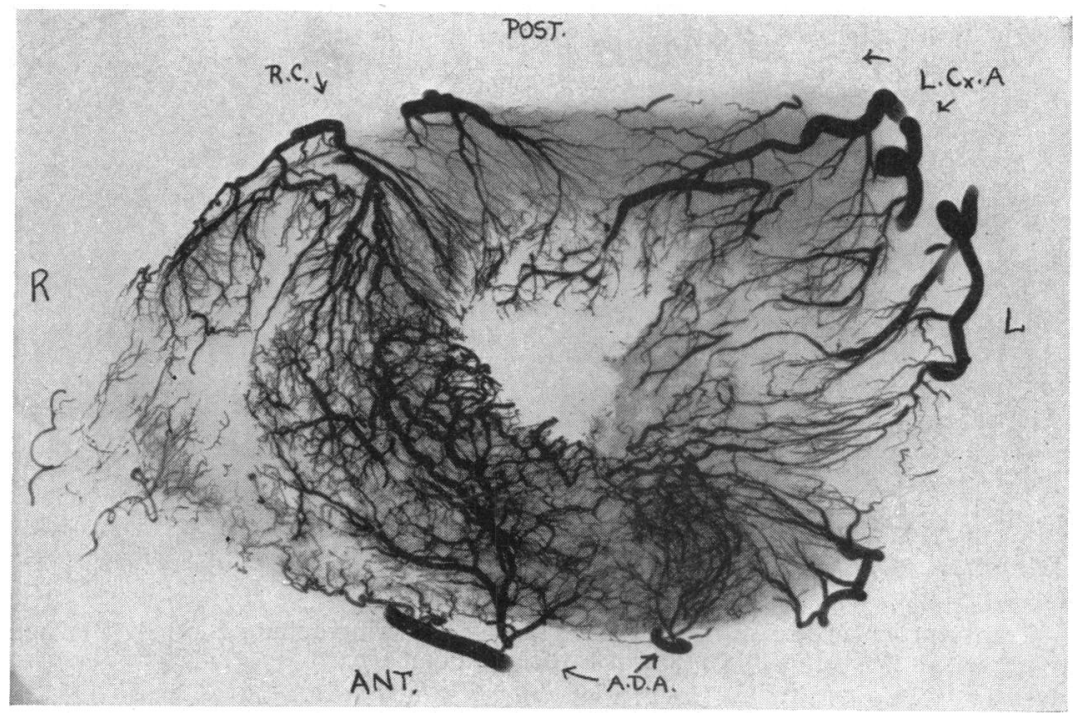

FIG. 4.-Transventricular section (Case H.E.). The deep vessels distal to old anterior descending artery occlusion (A.D.A.) show adaptive enlargement. There is also slight-moderate enlargement of deep vessels in neighbouring territories which had good blood supply. 


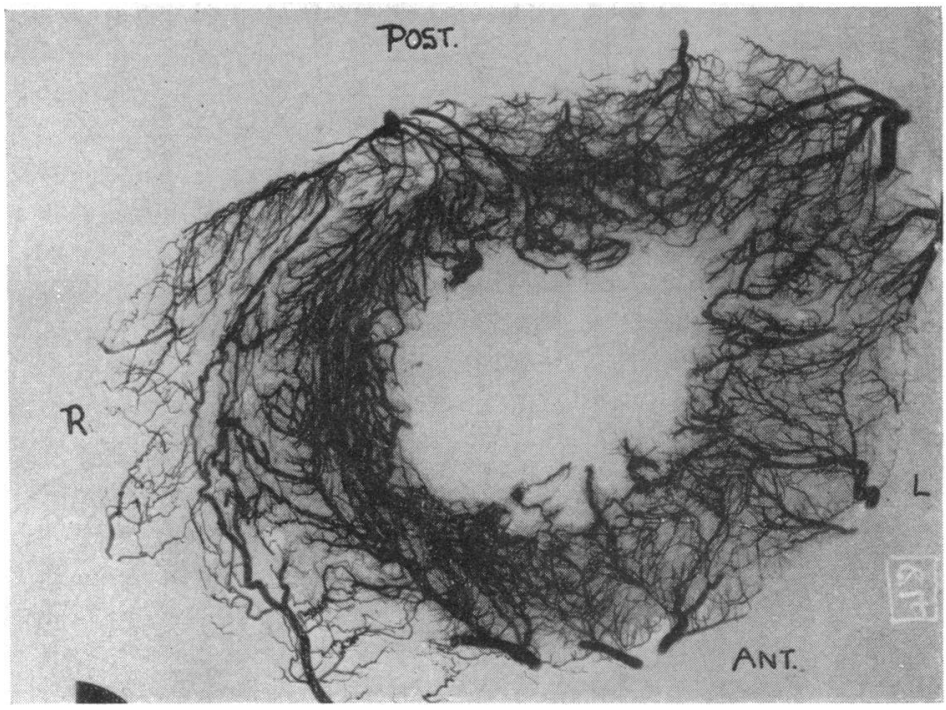

FIG. 5.-Transventricular section (Case B.M.). Old-standing widespread obliterative coronary artery disease caused generalized ischæmia of the heart. Extensive and generalized enlargement of the vessels of the deep plexus of the left ventricle is shown.

antero-septal in position and had resulted from anterior descending artery occlusion in the absence of obstruction of the other coronary arteries. At the time of death very considerable enlargement of communicating channels linked the vessels of the affected area with those of well-provided neighbouring territories. Of particular note was the part played by the deep communicating vessels of the interventricular septum and the subendocardial plexus of the left ventricle. The anastomotic pattern was similar to that represented in Fig 6, BB. Before its final occlusion the anterior descending artery had been narrowed to about $2 \mathrm{~mm}$. in diameter, i.e. to about one-half its original lumen diameter.

It was of course not possible to determine in this instance what proportion of the anastomotic adaptation had taken place subsequent to occlusion, nor indeed the duration of the changes save that they were old-standing. A considerable measure of protection must, however, have been afforded by the collateral circulation already existing at the time. Unfortunately, no opportunity was afforded in this series of observing fresh regional myocardial infarction that was as restricted in its distribution as the old-standing damage found in this and similar cases. This should not of course occasion surprise, for it was evident that lesions of this order were commonly survived.

(3) A 73-year-old woman (B.M.). In some instances of obliterative coronary artery disease of long standing, very extensive enlargement of the deeper vessels of the left ventricle may be found. Fig. 5 illustrates the order of change in these vessels which may be displayed in a transventricular section. In this case there had been severe and progressive symptoms of ischæmic heart disease for some ten years. All the main coronary arteries had been compromised by disease, as may be appreciated by reference to Fig. 10. Although only the more distal of two occlusions of the right coronary artery (2) was still complete at death, there was little doubt that the canalized occlusions of the anterior descending artery (4) and of the proximal part of the right coronary artery had formerly been complete. This may well have been the case with the left circumflex artery as well (3).

The total blood flow entering the coronary circulation must have been severely curtailed on account of these obstructive lesions. It was also evident that this impoverished blood supply had been equitably distributed to all parts of the heart through anastomotic channels.

Apart from one unusually large superficial communication between a marginal branch of the left circumflex artery and the anterior descending artery in the region of the apex, superficial communications over the left ventricle were of relatively small scale. A large anastomosis in the atrio-ventricular groove is also shown. 

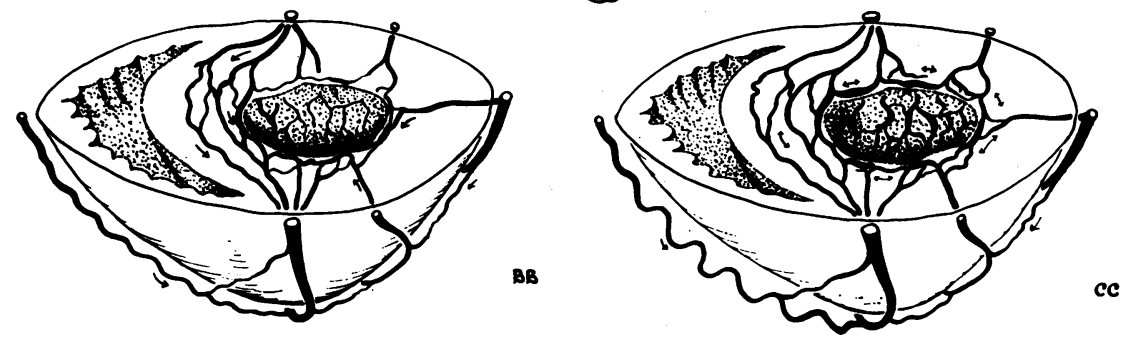

ispres.

Fig. 6.-Distribution of ischæmic myocardial damage (A, B, C) and related anastomotic patterns (AA, BB, CC.). (A) Massive regional myocardial infarction, involving most of the territory of the occluded artery. (B) Sub-total regional myocardial infarction. (C) Inner zonal 'ring' infarction of the left ventricle: focal necrosis. (AA) Anastomic pattern, little or no departure from normal. (BB) Local enlargement of anastomoses provides a measure of collateral blood supply from neighbouring unobstructed arteries. (CC) Generalized enlargement. 


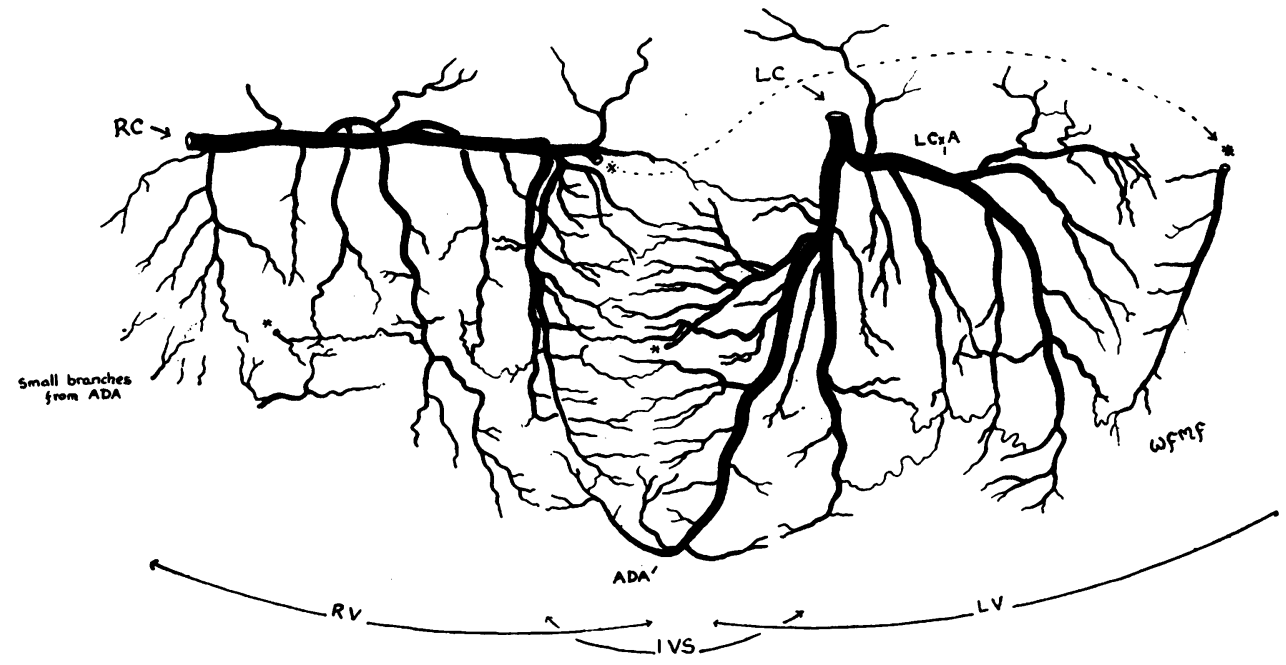

Fig. 7.-Arterial diagram of a healthy coronary 'tree'. Note smoothly tapering main vessels and their branches, with communications of small scale only.

The subendocardial plexus on the other hand had been converted into a network of widely dilated, intercommunicating channels occupying the entire inner zone of the left ventricle. Ischæmic myocardial damage was likewise restricted to the deeper layers of the left ventricle, and was patchy and diffuse. The pattern of anastomotic enlargement and the distribution of myocardial damage conformed to the appearances shown in Fig. 6, C, CC. It seemed highly probable that the distribution and limited extent of myocardial

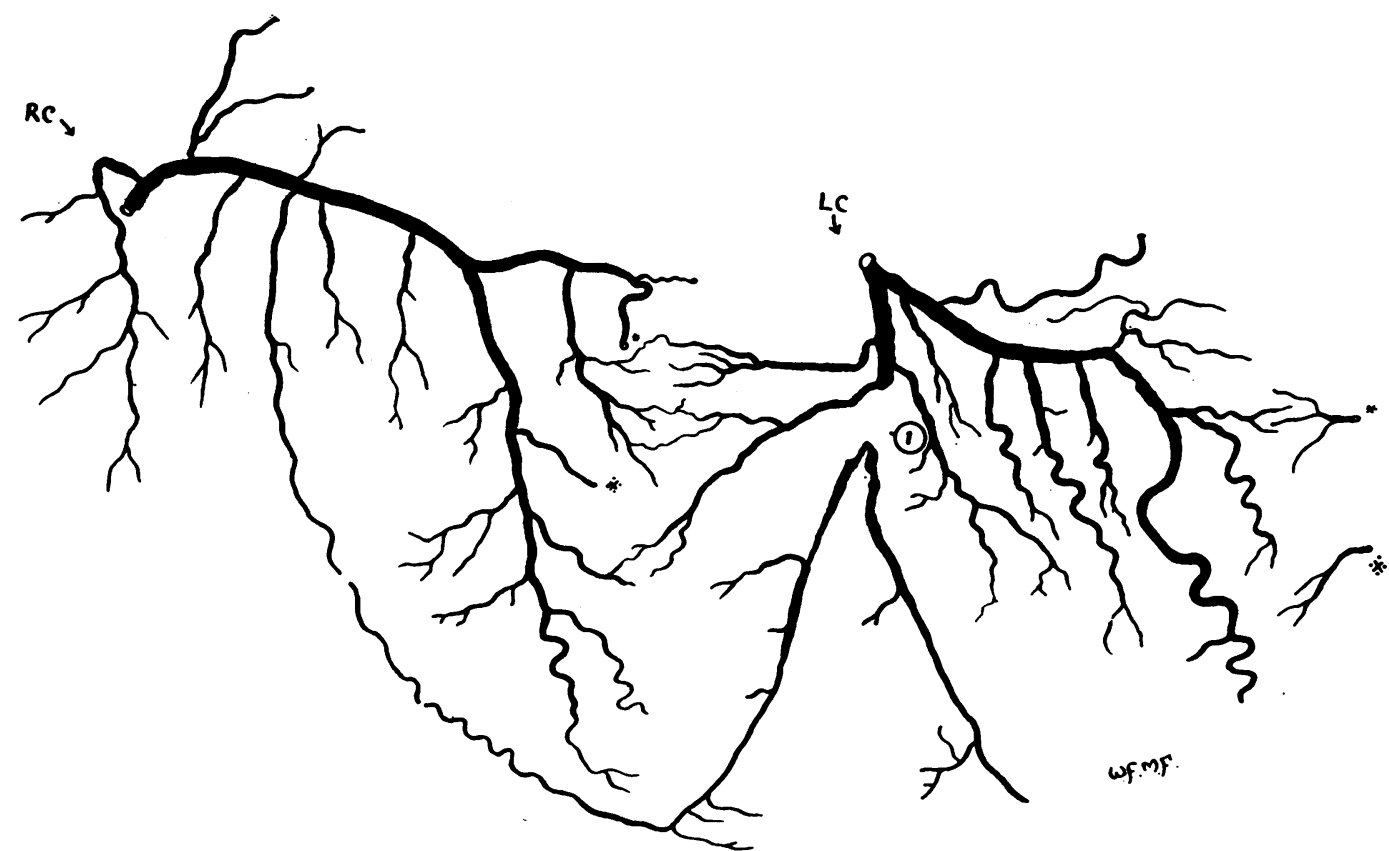

FIG. 8.-Arterial diagram (Case J.C.). Occlusion of anterior descending artery (1) of 8 days' duration. Enlarged anastomosis between right coronary artery and anterior descending artery at the apex was insufficient to prevent massive infarction. Only slight communication elsewhere. 
damage was largely determined by the extensive changes in the deeply-placed coronary anastomoses (Fulton, 1956).

\section{General Conclusions AND Discussion}

1. Protective Effect of Anastomoses Enlarged Before Occlusion. The findings in this investigation indicated that the collateral circulation readily available at the time of coronary artery occlusion was the most important factor limiting the extent of the myocardial damage. It was evident that extensive departure from the dimensions and pattern found in the normal coronary circulation (see Fulton, 1963a) was required before much degree of protection was afforded. The observations are summarized in Fig. 6 which has been drawn to scale. Evidence has also been presented elsewhere (Fulton, 1963b, 1964a) which bears on the dimensions of the anastomoses concerned and the time required for their enlargement.

In general it may be stated that in the normal heart anastomoses up to $200 \mu$ in diameter were abundant and of $300 \mu$ in diameter infrequent. In minor departures from the normal pattern, corresponding to Fig. 6, AA, anastomoses $200-500 \mu$ in diameter were frequent, but larger than this were uncommon. Sudden complete occlusion of a major coronary artery in this setting tended to result in massive regional myocardial infarction and death. In no instance in the present series, however, did infarction actually involve so large a portion of the arterial territory as depicted in Fig. 6, A.

Where communicating vessels of the order of $500-800 \mu$ diameter were frequent, as indicated in Fig. 6, BB, a considerable measure of protection had been afforded, so that acute occlusion of a major coronary artery resulted in regional infarction of considerably restricted extent. The event was invariably survived in the present series and accordingly considerable reservation must be expressed in offering comment on the dimensions of the collateral vessels at the time of coronary artery occlusion.

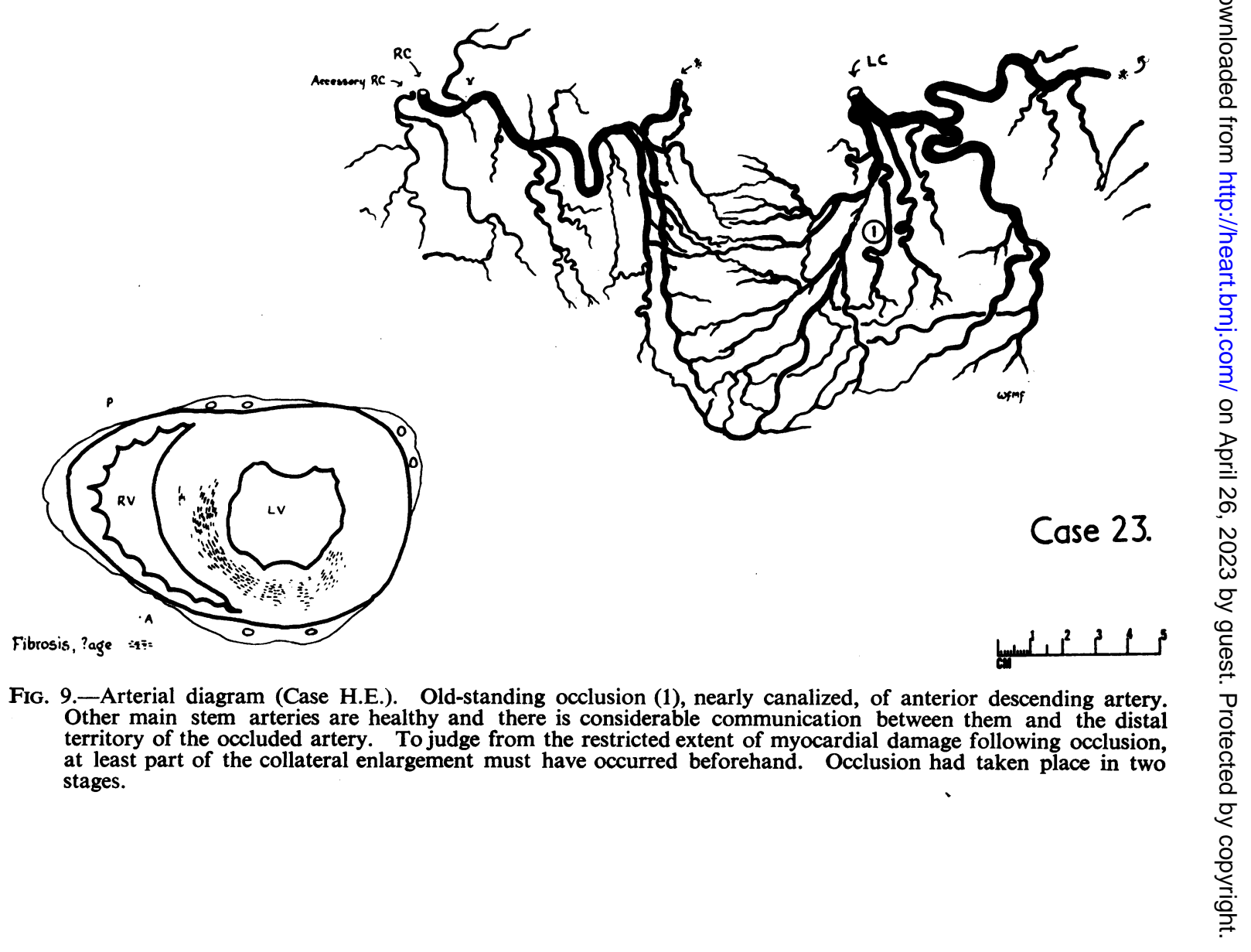




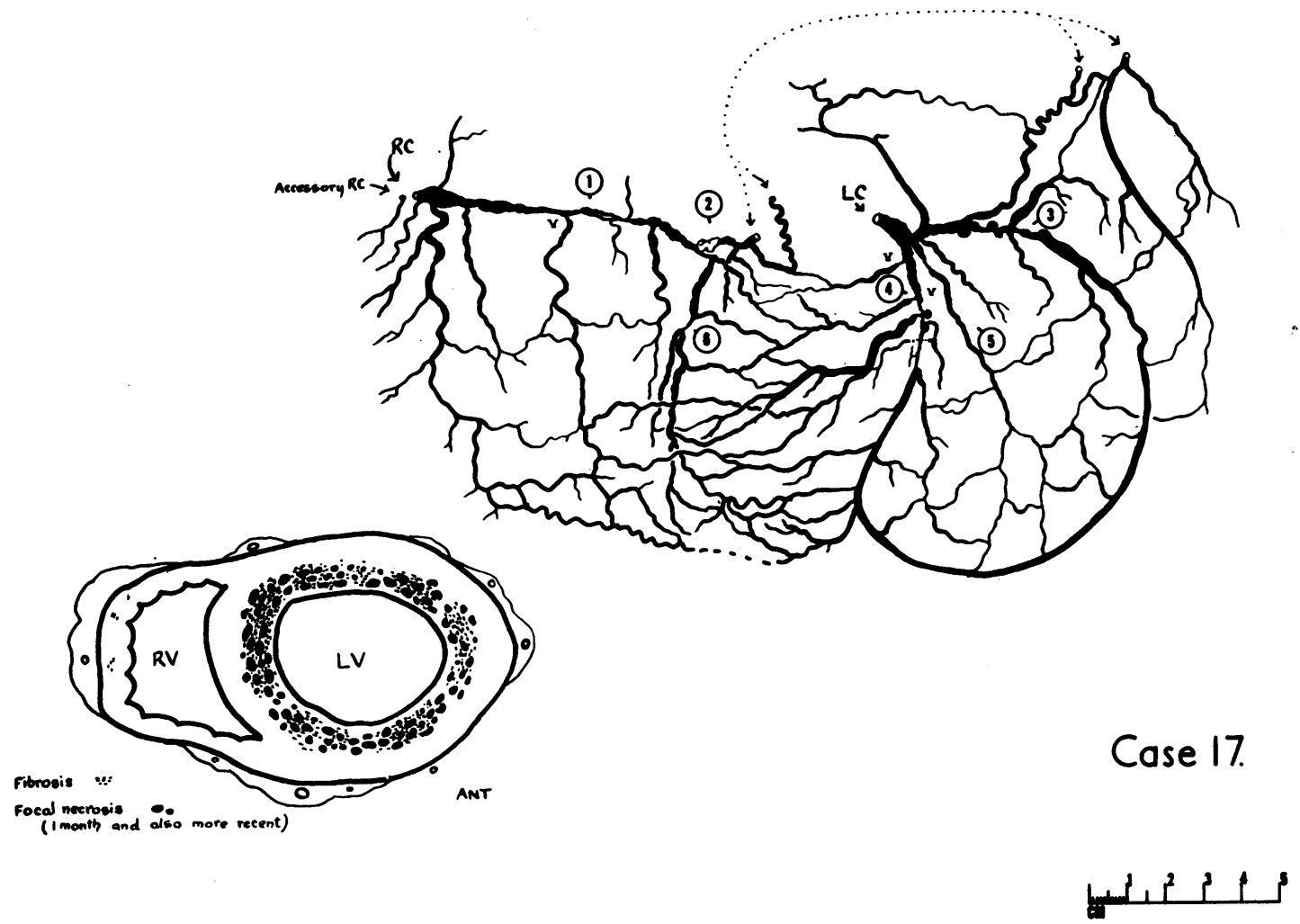

FIG. 10.-Arterial diagram (Case B.M.). Widespread occlusive disease of the coronary arteries, all but one of the occlusions (2) being canalized by the time of death. Occlusions of right coronary artery (1) and (2), and its posterior descending branch (6), of the left circumflex artery (3) and its branch (5) and of the anterior descending artery (4). The anastomotic enlargement that has been provoked is extensive and mainly involves the deep plexus. An exceptionally large superficial communication connects the left circumflex and anterior descending arteries. Myocardial damage was of focal nature in the inner zone of the left ventricle.

In the situation typified by Fig. 6, C, CC, not only were anastomoses $500-800 \mu$ in diameter numerous but smaller numbers of still larger calibre were also present. The importance of a few channels of wide bore, relative to large numbers of small bore, requires to be stressed (Fulton, 1964b). In this setting coronary artery occlusion did not appear to have provoked regional myocardial damage. Instead, focal necrotic and fibrotic lesions were found widely distributed throughout the inner zone of the left ventricle at death. It was evident that anastomotic developments of this order had protected the heart from extensive infarction until terminally, but on account of obliterative disease of the main coronary arteries ischæmia could not be entirely relieved. The collateral adaptation, however, did achieve an equitable distribution of greatly reduced total blood supply. Myocardial ischæmia was generalized. When finally coronary insufficiency became intolerably severe, many focal areas remotely placed from their source of blood supply underwent necrosis. In aggregate these formed a ring of infarction in the inner zone of the ventricle.

2. The Withdrawal of Collateral Support. In the examples considered so far, the protective effect of collateral development was assessed by noting the degree to which muscle damage was prevented following coronary artery occlusion. Sometimes, however, light was thrown on this subject from a different angle. This occurred when the relief blood supply to an ischæmic area had been carried by an unobstructed artery, which in its turn was blocked. With the collateral supply thus cut off, the myocardial damage that ensued might involve not only the territory of the freshly occluded vessel 


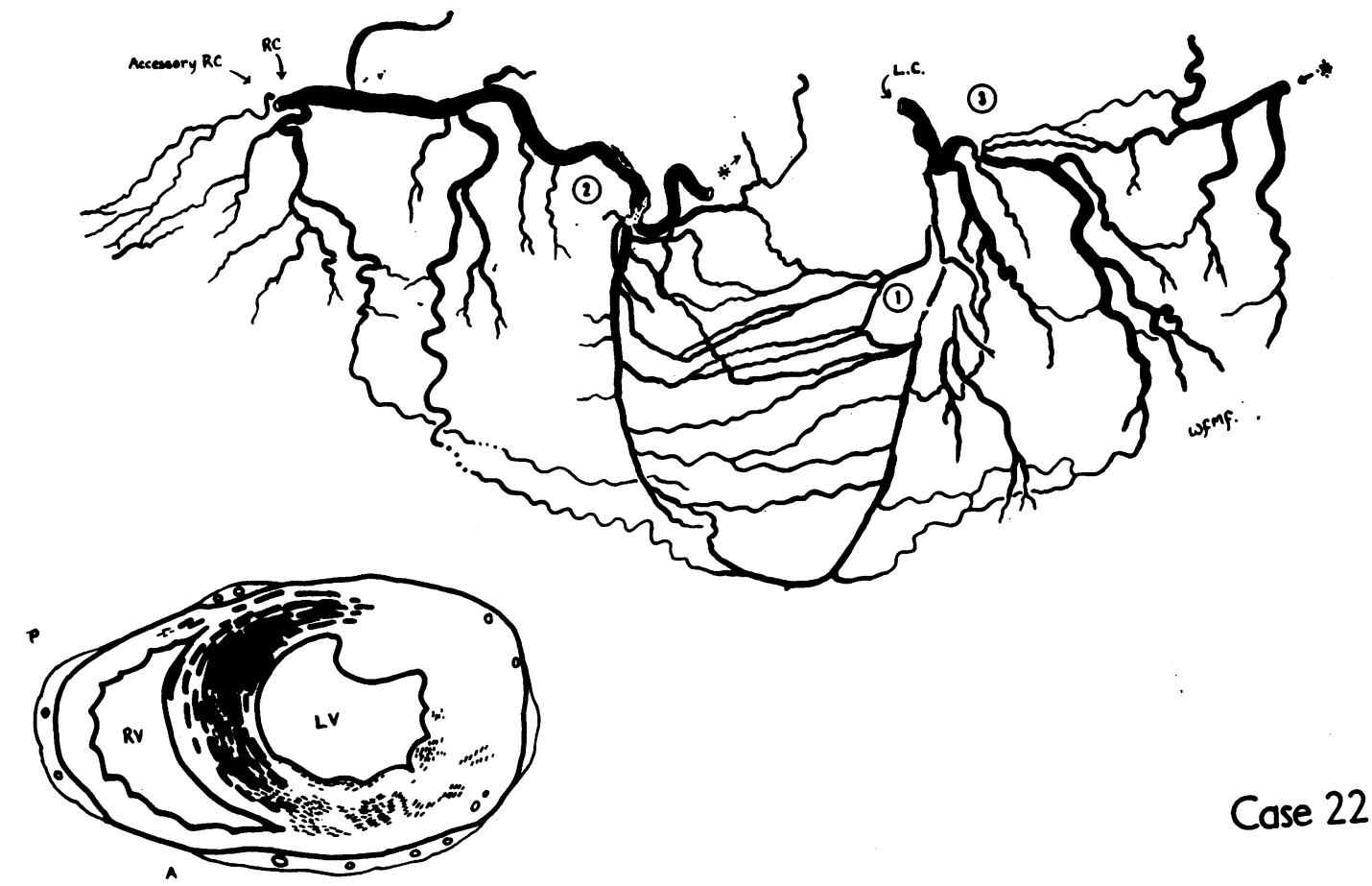

Fig. 11.-Arterial diagram (Case T.B.). Occlusion of the anterior descending artery (1) took place in two stages, the most recent being two years before death. There was also old severe narrowing (3) of the left circumflex artery of unknown duration. Extensive anastomoses brought blood supply from the large and unobstructed right coronary artery to the territory of the anterior descending artery. When this collateral blood supply was cut off by dissection and thrombosis of the right coronary artery (2) extensive infarction occurred in its own territory and also in that of the anterior descending artery.

but also that of its neighbour. The degree to which it did so was taken as a measure of the former importance of the occluded artery for the blood supply of the neighbouring territory. The following case is illustrative of this situation, which is not uncommon.

Case T.B., a 66-year-old man. It will be helpful to make reference to the drawing of the arterial tree and the distribution of myocardial damage (Fig. 11). The following sequence of events was reconstructed from the clinical features, and from detail of the myocardial damage, coronary artery occlusions, and anastomotic development.

(1) Early in the course of the disease there had been thrombotic narrowing of the right coronary artery. Myocardial damage had been trivial and was represented by focal fibrosis in the posterior basal portion of the left ventricle. The episode appeared to have passed unnoticed clinically.

(2) Severe enduring anterior chest pain occurred for the first time two years before death. There were no premonitory symptoms. There is little doubt that this episode was caused by complete thrombotic occlusion of the anterior descending artery (1). The mass of the myocardium that was infarcted, however, was only about one-third of the arterial territory anatomically at risk. The remaining two-thirds were spared through the agency of collateral circulation which had brought relief blood supply across the interventricular septum from the right coronary artery.

It is tempting to suppose that the state of preparedness that provided an immediately available relief supply at this time had in turn been provoked by the earlier narrowing referred to above. At this earlier stage it is likely that a gradient of pressure had favoured blood flow from the anterior descending artery to the territory of the right coronary artery distal to the point of narrowing. When the anterior artery was itself occluded, the gradient and direction of flow were reversed, and the collateral blood supply so provided was probably life-saving. Doubtless over the ensuing two years this collateral supply would become increasingly abundant as the channels which carried it enlarged. Finally, however, their sufficiency was put to the test. 
(3) Two years after the anterior occlusion, the right coronary artery was itself completely blocked (2), and the relief blood supply to the anterior area was withdrawn. As a result of right coronary artery occlusion, massive infarction occurred in the territory of the anterior descending artery. Indeed, so far as could be judged, the extent of ischæmic damage to the myocardium in the territory of this artery that resulted from the withdrawal of collateral blood supply was considerably more extensive than the damage that had taken place when its own regional artery was obstructed in the first place.

This case illustrates several points. First, it points a lesson that must be kept in mind when interpreting the arteriographic findings: that the volume of collateral blood flow depends not only on the dimensions of the communicating vessels but upon the continued patency of the vessels supplying them. The circulatory conditions in this respect have often been radically altered shortly before death. Correct reconstruction of a case will depend, therefore, upon an accurate appreciation of the sequence of pathological events. This demands very detailed examination of the obstructive lesions, correlated with clinical events and with myocardial changes, both of which may be of service in assessment of the time relations.

Secondly, in addition to damage in its own territory, the occurrence of infarction in a neighbouring territory is not rare following coronary artery occlusion. This phenomenon has been observed by others including Saphir et al. (1935), Bean (1937), and Blumgart, Schlesinger, and Zoll (1941). Recent 'para-regional' (versus 'ipse-regional', Fulton, 1960) infarction following coronary artery occlusion occurred in 5 out of 21 cases with recent myocardial damage in my series. In 3 instances the damage was massive. It never occurred in a territory that had not previously been the seat of ischæmic damage. Previous occlusion of the artery anatomically supplying the distant region (the para-regional artery) was evidently a prerequisite to its occurrence.

Lastly, progressive obliteration of a coronary artery is not a truly gradual process but advances by recurrent episodes. When these episodes are separated by long intervals of time, encroachment on the arterial lumen is followed step by step by compensatory augmentation of the collateral blood supply. Sometimes it may happen, as in the case cited above, that channels are opened up by carrying a relief blood supply from a patent artery to a neighbouring artery which is temporarily obstructed. The same enlarged collateral channels may then be put to service in the reverse direction when the first artery in turn is overtaken by obstruction. More commonly, 'gradual' or episodic narrowing of a coronary artery, by the laying down of thrombus and intimal tissue, acts so to speak as an investment. Enlargement of anastomoses so provoked may lessen the extent of damage when finally occlusion withdraws all supply through the normal channels.

3. The Extent of Protection. The protective effect of 'gradual' occlusion was noted by Schlesinger (1938) and was later tested experimentally (Blumgart et al., 1950). In the young pig it was observed that prior narrowing of a coronary artery over a period of weeks protected the heart from infarction when the ligation was finally completed. In man also it has been stated that 'abnormal anastomoses . . . can reduce or even prevent entirely . . . the pathologic evidence of myocardial necrosis after coronary artery occlusion' (Zoll et al., 1952). In my own series there was only one complete occlusion (of more than a few hours' duration) of a main coronary artery supplying the left ventricle, which had failed to cause ischæmic damage. It was anatomically a small artery, and the occlusion was distally placed beyond the origin of a large and unobstructed branch. Complete occlusion of a small right coronary artery that supplied only the right ventricle likewise provoked no myocardial injury. There were however several instances in which the myocardial damage following coronary artery occlusions was of a focal nature only ( 7 out of 45 complete or canalized-once-complete main-stem occlusions). In the great majority of complete occlusions of the coronary arteries the myocardial damage was readily recognizable. This applied alike to lesions of old standing - which had been survived-and to recent lesions which had been the cause of death.

Altered conditions of blood flow consequent on coronary artery obstruction appear to be the most potent agency in promoting the enlargement of coronary arterial anastomoses (Fulton, 1964b). It is important to emphasize the sequence of events. Unless this is properly appreciated statements that hint at anastomoses arising where they are 'needed' (Schlesinger, 1938) may be 
misinterpreted when taken out of context. In my view, anastomotic enlargement takes place as a response to, and not as protection against, the effects of coronary artery obstruction. Enlargement of these channels may indeed be fortunate, but it should nevertheless be recognized that the process of enlargement is a fortuitous outcome of altered circulatory conditions. Being a sequel to occlusion, it need occasion no surprise that anastomotic development should lag behind the needs of the heart muscle, and that the advent of arterial occlusion should find the coronary circulation to a greater or lesser degree unprepared.

4. Compensatory Anastomotic Enlargement After Occlusion. While the extent of the anastomotic circulation immediately available at the time of coronary artery occlusion may have life-saving importance through limitation of the extent of damage in the territory of myocardium at risk, subsequent collateral developments are not without importance. As the volume of collateral blood flow increases under the abnormal pressure gradients created, or intensified, by arterial occlusion, the viability and the functional reserve of the surviving myocardium in the ischæmic area will become progressively more assured. Unless canalization of the arterial occlusion should result in a channel of sizeable dimensions, an augmented collateral circulation is the only natural agency that can directly improve the circulatory status of the myocardium. From what has already been said, and discussed at more length elsewhere (Fulton, 1964a), a considerable time is required. My findings support the opinion expressed by Blumgart et al. (1950) that the process requires many weeks, and that the development of a richer anastomotic circulation may be responsible for clinical improvement. Indeed, my own findings suggest that this process of compensation may continue not only for many weeks but possibly for many years-always with the proviso that the other coronary arteries and the coronary ostia are unobstructed at the time, and subsequently. The present investigation also supports the experimental finding that strong stimulation of coronary collaterals demands very severe restriction of the lumen of a coronary artery (Sewell, 1961).

\section{SUMMARY}

A series of 25 cases of advanced coronary artery disease with 34 controls was investigated post mortem by a method that included stereo-arteriography.

The relation between the extent and distribution of myocardial infarction following coronary artery occlusion was studied in relation to the pattern of anastomotic enlargement.

Distinction was drawn between regional and zonal myocardial infarction in regard to distribution. Where the degree of anastomotic enlargement showed little departure from that found in normal hearts, occlusion of a coronary artery was followed by massive regional infarction. In all cases muscle tissue at the margins of the affected territory was spared to a greater or lesser extent.

Where the coronary circulation had been converted into a network of wide intercommunicating channels, obliterative coronary artery disease involving all, or most, main stems had provoked zonal ischæmic damage in the deeper layers of the left ventricle. Despite severe generalized myocardial ischæmia the damage was of a multiple focal nature and was not extensive.

The importance of the deeply-placed anastomotic vessels of the subendocardial plexus of the left ventricle was emphasized by the findings of this series. It appeared that the deep plexus was largely responsible for determining the distribution and limited extent of myocardial damage in severe chronic generalized myocardial ischæmia. It also appeared to play an important part in limiting the extent of regional myocardial damage following acute coronary artery occlusion.

No opportunity was afforded of examining the anastomotic pattern shortly after regional myocardial infarction of very restricted extent. Such lesions tend to be survived and accordingly there were many examples of infarction of small scale among the lesions of older standing. In these instances the degree of anastomotic enlargement already present at the time of occlusion could not be distinguished from the enlargement that had taken place after, and had been provoked by, coronary artery occlusion. Observations are presented in the light of this reservation.

The relation of myocardial damage to anastomotic development is expressed diagrammatically and measurements of anastomoses are given. 
The part played by collateral circulatory developments subsequent to myocardial infarction are considered. Observations on 'infarction at a distance' are presented.

It is concluded that the most important single factor in determining the extent and distribution of myocardial infarction following coronary artery occlusion is the pattern of anastomotic enlargement present at the time.

The investigation was begun in the course of a research appointment in the University of Edinburgh, created on the initiative of Dr. Rae Gilchrist and sponsored by the Department of Health for Scotland. The original work was carried out in the Departments of Pathology in the University of Edinburgh under Professor A. Murray Drennan, in the Royal Infirmary Edinburgh, under Dr. R. F. Ogilvie, and in the Department of Anatomy under the late Professor J. C. Brash. The study was continued during the tenure of a lectureship in the Department of Materia Medica and Therapeutics in the University of Glasgow. To those mentioned and to many others, grateful acknowledgement is made for facilities afforded and for advice and criticism. The clinical records were carefully documented by members of the Department of Cardiology, the Royal Infirmary, Edinburgh, under Dr. Gilchrist. I am indebted to Mr. P. S. Waldie, Department of Clinical Photography, Stobhill General Hospital, Glasgow, for photographic reproduction of the line drawings and arteriograms.

\section{REFERENCES}

Bean, W. B. (1937). Infarction of the heart: a morphological and clinical appraisal of 300 cases. Amer. Heart J., $14,684$.

Blumgart, H. L., Schlesinger, M. J., and Zoll, P. M. (1941). Angina pectoris, coronary failure and acute myocardial infarction. J. Amer. med. Ass., 116, 91.

—, Zoll, P. M., Freedberg, A. S., and Gilligan, D. R. (1950). The experimental production of intercoronary arterial anastomoses and their functional significance. Circulation, $1,10$.

Fulton, W. F. M. (1956). Chronic generalized myocardial ischæmia with advanced coronary artery disease. Brit. Heart J., 18, 341.

- (1960). Observations on the coronary arteries: A study of the anatomy of the circulation of the human heart in health and disease, aided by stereoarteriography, together with observations on the microanatomy of coronary atherosclerosis and thrombosis, and notes on the pathogenesis of these conditions. M.D. Thesis, Glasgow.

(1963a). Arterial anastomoses in the coronary circulation. I. Anatomical features in normal and diseased hearts demonstrated by stereoarteriography. Scot. med.J. In the press.

(1963b). Arterial anastomoses in the coronary circulation. II. Distribution, enumeration and measurement of coronary arterial anastomoses in health and disease. Scot. med.J. In the press.

(1963c). Immersion radiography of injected specimens. Brit. J. Radiol., 36, 685.

- (1964a). The time factor in the enlargement of anastomoses in coronary artery disease. Scot. med.J. In the press.

- (1964b). The dynamic factor in enlargement of coronary arterial anastomoses, and paradoxical changes in the subendocardial plexus. Brit. Heart J., 26, 39.

Herrick, J. B. (1912). Clinical features of sudden obstruction of the coronary arteries. J. Amer. med. Ass., $59,2015$.

Hirsch, C., and Spalteholz, W. (1907). Coronararterien und Herzmuskel. Anatomische und experimentelle Untersuchungen. Dtsch. med. Wschr., 1, 790.

Saphir, O., Priest, W. S., Hamburger, W. W., and Katz, L. N. (1935). Coronary arteriosclerosis, coronary thrombosis, and the resulting myocardial changes. Amer. Heart J., 10, 567 and 762.

Schlesinger, M. J. (1938). An injection plus dissection study of coronary artery occlusions and anastomoses. Amer. Heart J., 15, 528 .

Sewell, W. H. (1961). Physiologic and technical requirements for experimental strong stimulation of coronary collateral arteries. Circulation, 24, 1036.

Zoll, P. M., Wessler, S., and Blumgart, H. L. (1951). Angina pectoris: a clinical and pathologic correlation. Amer. J. Med., 11, 331 . , $\frac{\text { cardiovasc. 'Dis., 21, 118. }}{\text { c., }}$, and Blumgart, H. L. (1952). Interarterial coronary anastomoses. Mod. Conc. 